\title{
Effects of a School-based Intervention Program on Attitude and Knowledge of Household Members Towards a Smoke-free Home: a Cluster Controlled Trial
}

\author{
Nirun Intarut, Virasakdi Chongsuvivatwong*, Edward McNeil
}

\begin{abstract}
Background: A school-based smoke free home (SFH) program is useful in empowering the mother and child to reduce secondhand smoke exposure but the effects of pretesting on knowledge and attitude has been largely ignored. We aimed to test whether such a program can be effective in Southern Thailand with an additional assessment of the net effect of the pretest. Materials and Methods: A Solomon four-group design was used. Twelve rural primary schools were assigned to one of the four conditions (each with 3 schools): intervention with and without a pretest, control with and without the same pretest. The intervention was performed in the classroom and home over a period of 1 month. Outcomes were assessed at baseline and 3 months after the intervention on whether the home was smoke free and related knowledge and attitude. Results: The intervention could lead to a smoke-free home without statistical significance. Attitude, knowledge and self-confidence on creating a smoke-free home, and self-confidence in avoidance of secondhand smoke exposure and persuading smokers to not smoke in their home were significantly improved. No pretest effect was observed. Conclusions: Gain in attitude, knowledge and self-confidence among family members from the brief school-based education should be enhanced by other measures.
\end{abstract}

Keywords: Smoke-free home - school-based educational intervention - Solomon four-group - Thailand

Asian Pac J Cancer Prev, 17 (3), 1235-1242

\section{Introduction}

Secondhand smoke exposure (SHSe) can cause many health problems such as respiratory disease, cancer, and cardiovascular disease in non-smokers, especially in infants and children (World Health Organization, 2009; Oberg et al., 2011; Gao et al., 2013; Pimhanam et al., 2014; Zulkifli et al., 2014; Lee et al., 2015). The two main strategies for SHSe reduction are legislation and public education. Public education has been used to increase awareness of the dangers of SHSe on health consequences, and legislation has been used for controlling smoking in public places (World Health Organization, 2013). Smoking in the home cannot be prohibited by law, however it has been shown that one way to reduce SHSe is by promotion of a smoke-free home (SFH) (Greenberg et al., 1994). The effectiveness of education programs for a SFH vary depending on the intervention strategy, population, setting, and health conditions of the target population (Gehrman and Hovell, 2003). Several education programs to reduce SHSe and to create a SFH have been implemented in clinical settings with a child's chronic illness (Task Force on Community Preventive, 2001). In a schoolbased program (Blanch et al., 2013), students were used to be a change agent in creating a SFH where they gain knowledge through health education in classrooms. Educating students about creating a SFH might be an effective way to reduce SHSe and to improve the health of non-smokers among family members. Therefore, this study used students to be a change agent in creating a SFH.

In an evaluation of an education program, one often compares knowledge and attitudes pre- and postintervention (Crone et al., 2003; Tahlil et al., 2013). The pretesting process itself may unknowingly stimulate the participants, to seek the knowledge or subsequently change their attitude. The pretest may also modify the effect of an intervention. Thus, a simple pre- and post- test comparison may overestimate the effect of the intervention. The Solomon four-group design can overcome these effects (Solomon, 1949). Although this design has been used in many studies (McCambridge et al., 2011), it has rarely been used in studies assessing the effect of an intervention to reduce SHSe in the home.

Despite continuous smoking prevention activities, the prevalence of secondhand smoke exposure (SHSe) in homes in Thailand is $36 \%$, especially in Southern Thailand where the prevalence of smoking and SHSe is the highest in the country (Tobacco Control Research and Knowledge Management Center, 2012). While antismoking education has been implemented at the school level, attempts to 
encourage SFH has never been done. Thailand as a whole has reformed basic education for over a decade to enhance student creativity, a so called "child-centered education" (Israsena and Texas, 2007). We hypothesized that combining school education on smoking with parental concurrent education can lead to SFH environment both knowledge and attitude and lead to SFH. Evaluation in this study was done with and without pretest for the above reason. The aim of this study was to evaluate whether the aforementioned intervention is effective and whether pretesting has an independent effect on the intervention.

\section{Materials and Methods}

\section{Study design and participants}

The Solomon four-group design used in this study is summarized in Figure 1. Each group contained 3 schools (clusters). Group 1 (G1) and Group 3 (G3) were given the intervention with and without pretesting, respectively. Group 2 (G2) and Group 4 (G4) acted as the control with and without pretesting, respectively. The pretesting period was August-September, 2014. The intervention was given in September 2014, and the post-testing period was January-February, 2015. Pre-testing was assessed only in G1 and G2 while the post-test was assessed in all the groups.

All public schools in Hatyai district were eligible for the study. Of 50 schools invited to participate, 12 (24\%) agreed to join and were included in the study. We conducted a cluster controlled trial in which participating schools were assigned into the above-mentioned four groups. Initially, a school, which is the primary unit under intervention, was considered to be randomly allocated into one of the four groups. Randomized allocation was, however, not possible because all schools demanded the intervention. Finally, the first 6 schools were allocated to the intervention arm ( 3 with and without pretest) and the remaining were given the intervention after the endline data collection was completed. In each school, all $4^{\text {th }}$ - to $6^{\text {th }}$-grade students aged between 9 and 12 years were recruited. After giving consent, students were requested to complete a baseline questionnaire. Additionally, sealed

Table 1. Session of Smoke-free Home Intervention in the Classroom

\begin{tabular}{|c|c|}
\hline Session Learning objectives and materials & Activity \\
\hline \multicolumn{2}{|l|}{$1^{\text {st }}$ week } \\
\hline Objective & Classroom \\
\hline $\begin{array}{l}\text { To recognize the harms of second-hand } \\
\text { smoke exposure and smoking; } \\
\text { the danger of smoking in their home }\end{array}$ & -Teaching about the harms of exposure to SHS and smoking \\
\hline Materials & $\cdot$ Negotiation with their family for creating SFH \\
\hline -Smoke-free home (booklet); & $\cdot$ Fill the name of disease related to exposure to \\
\hline $\begin{array}{l}\text { included an information about } \mathrm{SHSe} \text {, } \\
\text { reducing SHS in home; avoidance SHSe, } \\
\text { Steps of creating SFH, and quit line }\end{array}$ & SHS on the worksheet (1) \\
\hline -Steps to create a smoke-free home sheet & Family \\
\hline -Stickers and embed quit line & -Take the home sheet and discuss with family members \\
\hline $\begin{array}{l}\text {-Worksheet; (1) disease related to SHSe; } \\
\text { (2) SFH sheet }\end{array}$ & about set up the date of creating SFH \\
\hline \multicolumn{2}{|l|}{$2^{\text {nd }}$ week } \\
\hline Objective & Classroom \\
\hline -To be able to initiate activities leading to SFH & -Teaching about techniques to reduce SHS in their home \\
\hline Materials & $\begin{array}{l}\text { Drawing a picture and take it to paste on a door or } \\
\text { wall in their house. With quotation "Don't smoke in home, } \\
\text { it can hurt me" }\end{array}$ \\
\hline$\cdot$ Booklet & -Playing a game and role-play \\
\hline -Game and role-play & -Painting the colour on the SFH sticker \\
\hline -SFH stickers & Family \\
\hline$\cdot$ Promise form for creating SFH & $\begin{array}{l}\text {-Setting up the date of SFH and let smoker or } \\
\text { mother sign up on the promise form; if no smoker, } \\
\text { mother will sign up on the form. }\end{array}$ \\
\hline \multicolumn{2}{|l|}{ ·Paste sticker "Smoke-free home" } \\
\hline \multicolumn{2}{|l|}{$3^{\text {rd }}$ week } \\
\hline Objective & Classroom \\
\hline $\begin{array}{l}\text { To gain direct experience on avoiding SHSe } \\
\text { and refusing of tobacco use }\end{array}$ & -Teaching on how to avoid SHSe and refusing tobacco use \\
\hline Materials & $\begin{array}{l}\text { Sharing the experience with family members to } \\
\text { set up smoke-free home }\end{array}$ \\
\hline$\cdot$ Booklet & $\cdot$ Watching video \\
\hline $\begin{array}{l}\text { Video about avoidance SHSe, } \\
\text { creating a smoke free home, } \\
\text { and the danger of tobacco use }\end{array}$ & $\begin{array}{r}\text { Family } \\
-\end{array}$ \\
\hline \multicolumn{2}{|l|}{$4^{\text {th }}$ week } \\
\hline To get feedback about smoke-free home program & Classroom; Summarize the activities, feedback from students \\
\hline
\end{tabular}


envelopes containing an invitation letter, consent form, assent form, and a questionnaire were sent to the student's mother. If another family member currently smoked, they were also requested to complete the questionnaire. As the project aimed to create a SFH environment within the whole community, regardless of whether the household contained a current smoker or not, the mother was also requested to complete the questionnaire. However, if the mother was a smoker, the family was excluded from the study. Informed consent was obtained from all participants.

\section{Intervention program}

This study adopted the intervention modules described by Kegler and Alwan (Alwan et al., 2011; Kegler et al., 2012). The conceptual model in Kegler's study is based on social cognitive theory and the Transtheoretical Model. The intervention targets proximal determinants of behavioral capacity, self-efficacy, and outcome expectations related to creating a SFH and smoking behaviors. For Alwan's study, the SFH intervention was designed to encourage families to implement a SFH, and was delivered over a period of 6 months by students and trained health professionals.

The above modules were modified and applied to the classroom (students), and in the family (students, mothers and smokers). The intervention in the classroom consisted of four sessions each with the students and conducted by the teacher. The teachers were trained by a research team for 2 hours. The details of these sessions are summarized in Table 1. We provided a teachers' guide, and we also gave a SFH booklet to each student.

\section{Endline data collection}

Endline information was collected at the end of the intervention in a similar fashion to that at the baseline. In addition, for the intervention, the research team visited the participant's house to obtain the parent's feedback on the activities and observed whether the distributed media (sticker and poster) were placed as suggested.

\section{Outcomes measurement}

The primary outcome was assessed by asking the question: "In the past 7 days, did you see anybody smoke in your home" (Kegler et al., 2012). As the mother was considered more reliable, her answer was used if there

\begin{tabular}{|c|c|c|c|}
\hline Group & $\begin{array}{c}\text { Baseline assessment } \\
\text { (Pretest score) }\end{array}$ & Intervention & $\begin{array}{c}\text { Endline assessment } \\
\text { (Posttest score) }\end{array}$ \\
\hline G1 & O1 & $\mathrm{X}$ & $\mathrm{O} 2$ \\
\hline G2 & $\mathrm{O} 3$ & & $\mathrm{O} 4$ \\
\hline G3 & & $\mathrm{X}$ & $\mathrm{O} 5$ \\
\hline G4 & & & $\mathrm{O}$ \\
\hline
\end{tabular}

Figure 1. Solomon Four-group Design Lay Out. G1,G2,G3,G4 were 4 groups of primary schools, each with 3 members (schools) $\mathrm{O} 1$ and $\mathrm{O} 3$ presented baseline assessment at $\mathrm{G} 1$ and $\mathrm{G} 2$. $\mathrm{O} 2, \mathrm{O} 4, \mathrm{O} 5$ and $\mathrm{O} 6$ presented endline assessment at $\mathrm{G} 1, \mathrm{G} 2, \mathrm{G} 3$, and $\mathrm{G} 4$, respectively. X presented intervention was any discordance between the mother-child pair. The answers were reported as "yes, some days", "yes, everyday" and "no". The first two choices were combined into "yes" in the analysis. The mother was also asked the same question with only a "yes" or "no" answer. If the answer was "yes" then the number of days per week that the smoker smoked in the home was asked.

\section{Knowledge and attitude toward the harms of smoking and exposure to SHS}

Eight items on knowledge and 7 items on attitudes toward exposure to SHS were included in a self-completed questionnaire to assess these secondary outcomes (Kurtz et al., 2003; Huang et al., 2012). The details of these questions are shown in Annex I. The total scores ranged from 0 to 7 for knowledge and from 8 to 32 for attitude.

Self-confidence score in creating a SFH, avoidance of SHSe in the home and persuading smoker to not smoke in the home

To assess the creating a SFH self-confidence score, students and their mother were asked, "How much confidence do you have in making your home smokefree?". A Likert scale was used to measure this outcome, with scores ranging from 0 (no confidence) to 10 (highest confidence).

To assess the avoidance of SHSe in the home and any action to persuade the smoker to not smoke in the home, the students and their mother were asked "How much

Annex 1 Knowledge and attitude toward the harms of SHSe and smoking. The following items on knowledge and attitude were adopted form Kurtz et al and Huang et al and tested for reliability.

Attitude towards the harms of SHSe and smoking

Items: 8 questions, Cronbach's alpha: 0.80

Scores: 1 to 4, 1 (strongly disagree), 2 (disagree), 3 (agree), and 4 (strongly agree)

Reverse scoring: $3^{\text {rd }}, 6^{\text {th }}$ and $8^{\text {th }}$ question

Total scores: 8 to 32

1. Smoke from other people's cigarettes is harmful for me.

2. Smoking should be banned in all public places

3. Smoking helps exert one's imagination

4. Smoking makes people look cooler

5. Smoking is interesting

6. Everyone likes to get along with people who smoke

7. Parents should forbid children to smoke

8. Parents can smoke in front of children

Knowledge towards the harms of SHSe and smoking

Items: 7 questions, Cronbach's alpha: 0.73

Scores: True ( 1 score), False (0 score), and I do not know (0 score)

Reverse scoring: 2nd and 4th question

Total scores: 0 to 7

1. SHS causes lymphoma

2. SHS is associated with stroke

3. SHS is associated with asthma

4. SHS causes common cold

5. The younger one starts smoking, the higher the risk is for cancer

6. It is possible to be addicted to smoking

7. Smoking makes one's teeth turn yellow 
Nirun Intarut et al

confidence do you have in avoiding SHSe from smokers in your home?" and "When someone is smoking in the home, how much confidence do you have in telling/persuading them to not smoke in the home?" The level of confidence ranged from 0 (no confidence) to 10 (highest confidence) for each question.

Number of cigarettes consumed per day

The cigarette consumption of the smoker was assessed by asking the smoker: "On average, on the days you smoke, how many cigarettes do you smoke?"

\section{Sample size calculation}

We assumed there would be a $25 \%$ difference in the SFH status between the intervention and control groups after the 3-month intervention period. With a power of $80 \%$, a significance level of $5 \%$, a two-tailed, a design effect of 1.5 and a loss to follow-up rate of $20 \%$, at least 110 participants per group were needed. As there were 4 groups, 440 households were required in total.

\section{Statistical analysis}

The strategy of analysis was modified from the Braver and Braver algorithm (Braver, 1988) for testing the independent effects of the pretest and the intervention in the Solomon four-group design. A 2 (Group: Intervention, Control) x 2 (Condition: Pretest assessment, no pretest assessment) of the four posttest scores, and on interaction term between Group x Condition, was constructed for testing those effects. For the primary outcome, McNemar's chi square test for testing the increase in rate of SFH within groups 1 and 2 was performed. Multiple logistic regression was used to test the main effect of the intervention on SFH status. For secondary outcomes, multiple linear regression was used. All statistical assessments were two sided and evaluated at the 0.05 level of statistical significance. All statistical analyses were performed using $\mathrm{R}$ version 3.0.1 with epicalc package version 2.15.1. As students were

Table 2. Baseline Characteristics of Participants

\begin{tabular}{|c|c|c|c|c|c|c|}
\hline \multirow[t]{2}{*}{ Variables } & & \multicolumn{2}{|c|}{ With pretest } & \multicolumn{2}{|c|}{ Without pretest } & \multirow{2}{*}{$\begin{array}{c}\text { Total } \\
(\mathrm{N}=482)\end{array}$} \\
\hline & & $\begin{array}{l}\text { Intervention }(\mathrm{O} 1) \\
\qquad(\mathrm{N}=129)\end{array}$ & $\begin{array}{l}\text { Control (O2) } \\
\quad(\mathrm{N}=98)\end{array}$ & $\begin{array}{c}\text { Intervention (O5) } \\
\quad(\mathrm{N}=130)\end{array}$ & $\begin{array}{l}\text { Control (O6) } \\
(\mathrm{N}=125)\end{array}$ & \\
\hline \multicolumn{7}{|l|}{ Household } \\
\hline \multirow[t]{2}{*}{ Religion** } & Buddhist & $102(79.1)$ & $43(43.9)$ & $36(27.7)$ & $115(92.0)$ & $296(61.4)$ \\
\hline & Muslim & $27(20.9)$ & $55(56.1)$ & $94(72.3)$ & $10(8.0)$ & $186(38.6)$ \\
\hline \multicolumn{7}{|c|}{ Household income (Thai Baht) } \\
\hline$\leq 15,000$ & & $106(82.2)$ & $73(74.5)$ & $81(62.3)$ & $101(81.5)$ & $361(75.1)$ \\
\hline$>15,000$ & & $23(17.8)$ & $25(25.5)$ & $49(37.7)$ & $23(18.5)$ & $120(24.9)$ \\
\hline \multicolumn{7}{|c|}{ Number of smokers in home } \\
\hline One & & $66(85.7)$ & $56(77.8)$ & $56(84.8)$ & $71(79.8)$ & $249(81.9)$ \\
\hline Two or more & & $11(14.3)$ & $16(22.2)$ & $10(15.2)$ & $18(20.2)$ & $55(18.1)$ \\
\hline \multicolumn{7}{|c|}{ Family relationship score } \\
\hline Mean (SD) & & $11.6(3.1)$ & $11.7(3.1)$ & $11.1(3.2)$ & $11.1(3.3)$ & $11.3(3.2)$ \\
\hline \multicolumn{7}{|l|}{ Student } \\
\hline \multirow[t]{3}{*}{ Grade } & $4^{\text {th }}$ grade & $27(20.9)$ & $32(32.7)$ & $46(35.4)$ & $43(34.4)$ & $148(30.7)$ \\
\hline & $5^{\text {th }}$ grade & $47(36.4)$ & $35(35.7)$ & $52(40.0)$ & $34(27.2)$ & $168(34.9)$ \\
\hline & $6^{\text {th }}$ grade & $55(42.6)$ & $31(31.6)$ & $32(24.6)$ & $48(38.4)$ & $166(34.4)$ \\
\hline \multirow[t]{2}{*}{ Gender } & Male & $57(44.2)$ & $54(55.1)$ & $68(52.3)$ & $69(55.2)$ & $248(51.5)$ \\
\hline & Female & $72(55.8)$ & $44(44.9)$ & $62(47.7)$ & $56(44.8)$ & $234(48.5)$ \\
\hline \multicolumn{7}{|l|}{ Mother } \\
\hline Age (years); $\mathrm{N}$ & SD) & $39.2(7.4)$ & $38(7.4)$ & $39.2(7)$ & $39.1(8.0)$ & $38.9(7.4)$ \\
\hline \multicolumn{7}{|c|}{ Number of years attended school $* *$} \\
\hline$<7$ & & $57(44.2)$ & $42(42.9)$ & $42(32.3)$ & $66(52.8)$ & $207(42.9)$ \\
\hline$\geq 7$ & & $72(55.8)$ & $56(57.1)$ & $88(67.7)$ & $59(47.2)$ & $275(57.1)$ \\
\hline \multicolumn{7}{|l|}{ Occupation status } \\
\hline Unemployed & & $16(12.4)$ & $18(18.4)$ & $13(10)$ & $19(15.2)$ & $66(13.7)$ \\
\hline Employed & & $113(87.6)$ & $80(81.6)$ & $117(90)$ & $106(84.8)$ & $416(86.3)$ \\
\hline Smoker (All m & & $\mathrm{N}=75$ & $\mathrm{~N}=67$ & $\mathrm{~N}=66$ & $\mathrm{~N}=77$ & $\mathrm{~N}=285$ \\
\hline Age (years); $\mathrm{N}$ & SD) & $39.1(10.7)$ & $39(9.5)$ & $38.2(11.3)$ & $38.8(9.1)$ & $38.8(10.1)$ \\
\hline \multicolumn{7}{|c|}{ Number of years attended school } \\
\hline$<7$ & & $31(41.3)$ & $33(49.3)$ & $38(57.6)$ & $44(57.1)$ & $146(51.2)$ \\
\hline$\geq 7$ & & $44(58.7)$ & $34(50.7)$ & $28(42.4)$ & $33(42.9)$ & $139(48.8)$ \\
\hline \multicolumn{7}{|l|}{ Occupation status } \\
\hline Unemployed & & $9(12.0)$ & $16(23.9)$ & $8(12.1)$ & $6(7.8)$ & $39(13.7)$ \\
\hline Employed & & $66(88.0)$ & $51(76.1)$ & $58(87.9)$ & $71(92.2)$ & $246(86.3)$ \\
\hline \multicolumn{7}{|c|}{ Fagerstrom test for nicotine dependence score } \\
\hline Low & & $53(70.7)$ & $53(79.1)$ & $57(86.4)$ & $48(62.3)$ & $211(74.0)$ \\
\hline Moderate/high & & $22(29.3)$ & $14(20.9)$ & $9(13.6)$ & $29(37.7)$ & $74(26.0)$ \\
\hline
\end{tabular}

** $\mathrm{P}$ value $<0.05$ (testing between group $\mathrm{O} 1+\mathrm{O} 5$ and group $\mathrm{O} 3+\mathrm{O} 6$ ) 
clustered by school, we used the survey package to cope with the clustered nature in the final model. This was done using School ID as the primary sampling unit.

\section{Results}

Figure 2 shows the details of the flow diagram of participating schools and households in the study. In summary, a total of 12 out of 50 primary schools in Hatyai district, Songkhla province were invited and agreed to participate in the study. A total of 482 households (482 students and mothers; 285 smokers) participated and completed the study, 129 in the intervention with pretest group and without 98 group without pretest, 130 the control with pretest group and 125 in the control without pretest group.

Table 2 shows baseline characteristics of participants at the household and individual level. There were no differences in the number of smokers in the home, family relationship scores, school grade, student gender, age of mother and smoker, occupation status of mother, and number of years attended school by the smoker. However, there were differences in religion and number of years attended school by the mother. Due to the low school response rate and high socioeconomic clustering within a community, a balance of subject characteristics could not be achieved among the intervention groups.

\section{Primary outcome: the effect of intervention on SFH}

The percentage of smoke-free homes in the 4 groups at the baseline and endline (O1 to $\mathrm{O} 6$ in Figure 1) are shown in the top row of Table 3 . The distribution of percentage of
SFH and $95 \%$ confidence interval of participants in each school is shown in Figure 3.

In $\mathrm{G} 1$, the rate of SFH was non-significantly increased from $(\mathrm{O} 1) 41.9 \%$ at baseline to $(\mathrm{O} 2) 46.5 \%$ at endline (Difference: $4.65 \%, 95 \%$ CI: $-0.13,9.43$, P value: 0.06 ). Similarly a non-significant increased rate of SFH was seen in the control group $(\mathrm{G} 2)$ from $(\mathrm{O} 3) 31.6 \%$ to $(\mathrm{O} 4) 36.7 \%$ (Difference: $5.1 \%, 95 \%$ CI: $-1.5,11.7$, P value: 0.13 ).

Results based on survey regression analysis is shown

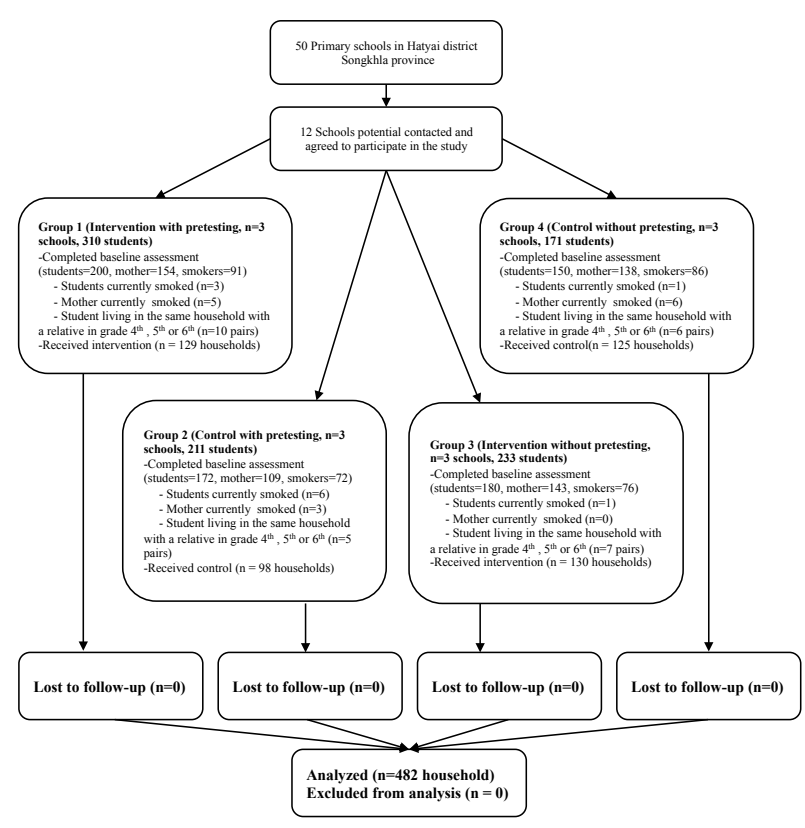

Figure 2. Study Flow Diagram

Table 3. Descriptive outcomes by pre-post assessment

\begin{tabular}{|c|c|c|c|c|c|c|}
\hline \multirow[t]{2}{*}{ Outcome } & \multicolumn{3}{|c|}{ Before } & \multicolumn{3}{|c|}{ After } \\
\hline & $\begin{array}{l}\text { Intervention } \\
\text { with pretest } \\
\quad(\mathrm{O} 1)\end{array}$ & $\begin{array}{c}\text { Control } \\
\text { with pretest } \\
\text { (O3) }\end{array}$ & $\begin{array}{l}\text { Intervention } \\
\text { with pretest } \\
\quad(\mathrm{O} 2)\end{array}$ & $\begin{array}{l}\text { Controlwith } \\
\text { pretest } \\
(\mathrm{O} 4)\end{array}$ & $\begin{array}{l}\text { Intervention } \\
\text { without } \\
\text { pretest (O5) }\end{array}$ & $\begin{array}{c}\text { Control } \\
\text { without } \\
\text { pretest }(\mathrm{O} 6)\end{array}$ \\
\hline \multicolumn{7}{|l|}{ Primary outcome (\%) } \\
\hline Smoke-free home (yes) & $\begin{array}{r}41.9 \\
(54 / 129)\end{array}$ & $\begin{array}{r}31.6 \\
(31 / 98)\end{array}$ & $\begin{array}{r}46.5 \\
(60 / 129)\end{array}$ & $\begin{array}{r}36.7 \\
(36 / 98)\end{array}$ & $\begin{array}{r}49.2 \\
(64 / 130)\end{array}$ & $\begin{array}{r}38.4 \\
(48 / 125)\end{array}$ \\
\hline \multicolumn{7}{|l|}{ Secondary outcomes } \\
\hline \multicolumn{7}{|l|}{ Knowledge on harms of SHSe } \\
\hline Student & $4.2(1.5)$ & $4.0(1.8)$ & $4.7(1.3)$ & $4.0(1.8)$ & $5.3(1.2)$ & $4.8(1.4)$ \\
\hline Mother & $4.4(1.4)$ & $4.1(3.5)$ & $4.6(1.3)$ & $3.9(1.8)$ & $4.4(1.5)$ & $4.3(1.6)$ \\
\hline Smoker & $2.7(2.4)$ & $3.1(2.3)$ & $3.3(2.5)$ & $3.2(2.3)$ & $2.5(2.6)$ & $2.3(2.2)$ \\
\hline \multicolumn{7}{|l|}{ Attitude on harms of SHSe } \\
\hline Student & $28.0(4.0)$ & $26.8(3.6)$ & $28.6(3.2)$ & $27.4(4.2)$ & $28.4(3.3)$ & $27.5(3.5)$ \\
\hline Mother & $27.5(3.9)$ & $26.5(4.3)$ & $28.2(2.9)$ & $28.2(3.4)$ & $28.1(3.5)$ & $27.4(3.7)$ \\
\hline Smoker & $16.1(4.1)$ & $19.1(4.6)$ & $17.7(3.4)$ & $19.1(4.2)$ & $14.2(3.8)$ & $15.5(4.2)$ \\
\hline \multicolumn{7}{|l|}{ Confidence } \\
\hline \multicolumn{7}{|l|}{-to create a SFH } \\
\hline Student & $7.3(2.3)$ & $7.0(2.4)$ & $7.6(1.9)$ & $6.1(2.9)$ & $7.7(2.2)$ & $6.9(2.6)$ \\
\hline Mother & $6.3(3.4)$ & $6.4(3.0)$ & $6.7(2.9)$ & $6.6(3.0)$ & $6.8(2.8)$ & $6.2(3.3)$ \\
\hline \multicolumn{7}{|l|}{ - to avoid of SHSe } \\
\hline Student & $14.8(4.6)$ & $14.3(4.4)$ & $15.7(3.8)$ & $13.8(4.9)$ & $16.6(3.1)$ & $15.3(3.6)$ \\
\hline Mother & $10.3(5.7)$ & $10.7(5.7)$ & $11.4(5)$ & $11(5.5)$ & $12.7(4.5)$ & $10.9(5.8)$ \\
\hline \multicolumn{7}{|c|}{-to persuade smoker not to smoke in the home } \\
\hline Student & $13.3(5.3)$ & $11.1(5.1)$ & $13.7(4.4)$ & $11.1(5.2)$ & $15.2(3.3)$ & $14.2(4.3)$ \\
\hline Mother & $9.5(6.1)$ & $9.4(5.4)$ & $11.6(4.2)$ & $10.1(5.3)$ & $12.0(4.6)$ & $10.1(5.3)$ \\
\hline Number of cigarettes smoked per day & $7.9(5.8)$ & $7.0(5.3)$ & $6.2(4.3)$ & $6.6(4.7)$ & $8.7(5.8)$ & $8.3(5.5)$ \\
\hline
\end{tabular}


Table 4. Summary of Result from Testing on Primary and Secondary Outcomes

\begin{tabular}{|c|c|c|}
\hline Variable & Pretest effect & Main effect (Intervention vs control) \\
\hline Primary outcomes & $P$ value & Odd ratios $(95 \% \mathrm{CI})$ \\
\hline Smoke-free home & 0.68 & $1.52(1.00,2.26)$ \\
\hline \multicolumn{3}{|l|}{ Secondary outcomes } \\
\hline Attitude score & & Difference of mean $(95 \% \mathrm{CI})$ \\
\hline Student & 0.23 & $0.50(0.22,0.78)^{*}$ \\
\hline Mother & 0.17 & $0.32(-0.37,1.00)$ \\
\hline Smoker & 0.91 & $-1.18(-3.5,1.14)$ \\
\hline \multicolumn{3}{|l|}{ Knowledge score } \\
\hline Student & 0.08 & $0.50(0.22,0.78)^{*}$ \\
\hline Mother & 0.10 & $0.47(0.24,0.69)^{*}$ \\
\hline Smoker & 0.65 & $0.17(-0.37,0.71)$ \\
\hline \multicolumn{3}{|l|}{ Creating SFH confidence score } \\
\hline Mother & 0.84 & $1.22(0.48,1.96)^{*}$ \\
\hline Smoker & 0.58 & $0.36(-0.17,0.89)$ \\
\hline \multicolumn{3}{|c|}{ Avoidance of SHSe in home confidence score } \\
\hline Mother & 0.57 & $1.64(0.24,3.04)$ \\
\hline Smoker & 0.30 & $1.19(-0.06,2.44)$ \\
\hline \multicolumn{3}{|c|}{ Persuading smoker to smoke outside the home confidence score } \\
\hline Mother & 0.99 & $2.04(0.69,3.39) *$ \\
\hline Smoker & 0.72 & $1.71(0.61,2.80)^{*}$ \\
\hline Number of cigarettes smoked per day & 0.13 & $0.09(-0.89,1.07)$ \\
\hline
\end{tabular}

* P value $<0.05$; All outcomes adjusted for pretest assessment, religion and number of years attended school of mother

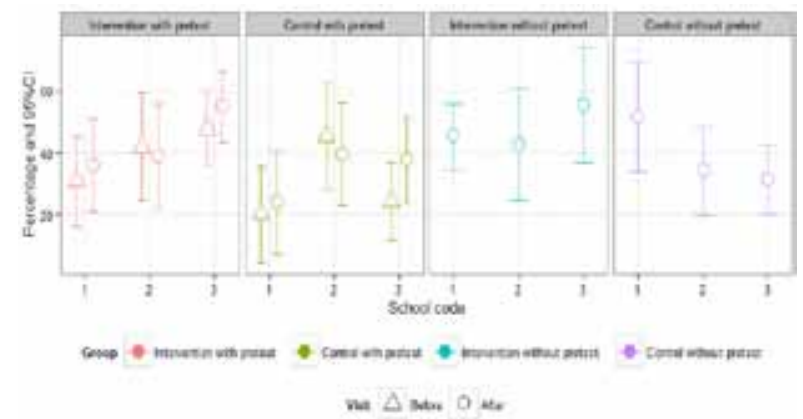

Figure 3. Percentage of Smoke-free Home Status by Schools and Intervention Groups

in Table 4. After adjusting for religion and mothers schooling years, there was non-significant effect of the intervention on SFH (OR: 1.52, 95\% CI: 1.00, 2.26).

\section{Secondary outcomes}

The pretesting effect was not statistically significant on any testing on group of subject. There was a positive effect of knowledge toward exposure to SHS and smoking among the students (Difference: 0.50,95\% CI: 0.22, 0.78) and their mother (Difference: 0.47, 95\% CI: 0.24, 0.69). Students in the intervention group had higher knowledge than those in the control group. No significant differences were observed for the smokers (Difference: 0.17, 95\% CI: $-0.37,0.71)$. Attitude toward the harms of SHSe and smoking. A positive effect of intervention was observed among students (Difference: 0.50, 95\% CI: 0.22, 0.78). No significant effect was found on attitude toward the harms of SHSe and smoking among the student's mother (Difference: $0.32,95 \%$ CI: $-0.37,1.00$ ), and smokers $(-1.18,95 \%$ CI: $-3.5,1.14)$.

There was a significant positive effect of the intervention on self-confidence scores in creating a SFH among students (Difference: 1.22, 95\% CI: 0.48, 1.96) but not among their mothers (Difference: $0.36,95 \%$ CI: -0.17 , 0.89). For avoiding SHSe in home confidence scores, a significant positive effect of the intervention was observed among the students (Difference: 1.64, 95\% CI: 0.24, 3.04) but not among their mothers (Difference: $1.19,95 \% \mathrm{CI}$ : $-0.06,2.44)$. For persuading smoker to smokes outside the home confidence scores, there were significant positive effects of the intervention among students (Difference: 2.04, 95\% CI: 0.69, 3.39) and their mothers (Difference: 1.71, 95\% CI: 0.61, 2.80).

Among households containing smokers, there was no significant difference in the number of cigarettes smoked by smokers between the intervention and control groups (Difference: 0.09, 95\% CI: -0.89, 1.07).

\section{Discussion}

Our findings show that the intervention improved attitude towards the harms of SHSe and smoking and self-confidence scores in creating a SFH and avoiding SHSe among schoolchildren. Both schoolchildren and their mother increased their self-confidence scores for knowledge and ability to persuade smokers not smoke in their home. Pretest sensitization was not observed.Among smokers, there was no effect of the intervention on any outcome. This school-based intervention program could not improve SFH status. Of various outcomes taken on the students and their mother, those on attempts to avoid SHSe and self-confidence scores to persuade smokers to not smoke inside the home are most promising.

Previous interventions to create a SFH and reduce SHSe in home in the past have given mixed results. One school-based study (Blanch et al., 2013) and one family-based study (Herbert et al., 2011) failed to detect a difference between the intervention and control groups. On the other hand, two hospital-based studies (Harutyunyan 
et al., 2013; Yilmaz et al., 2013) and one family-based study (Kegler et al., 2015) reported significant effects of their interventions aiming to promote a SFH. A SFH is, perhaps, too hard to achieve, especially by a sole schoolbased intervention without other enhancements. Students in general may not be a strong change agent.

However, students and their mothers can be empowered to gain self-confidence in their ability to persuade smokers to not smoke in the home and to avoid SHSe. Since family members had a higher self-confidence in avoiding SHSe, this effect might emerge as a social norm in their family to make their home to be smoke-free in the future. However, in a male-dominated society like rural Southern Thailand (Romanow, 2012), smokers, who mostly have a low education, tend to play down the importance of health and women's and children's right to health. This is consistent with previous findings that low socio-economic status was found to be associated with smoking in the home (King et al., 2013). Therefore, enhancing self-confidence of non-smoking family members to avoid SHSe in their home is important to protect themselves from the harms associated with SHSe.

In assessment of various psychometric parameters, questions are often employed to the same respondent before and after an intervention is given. Most previous interventions on smoking control, knowledge and attitude were often measured repeatedly (Harutyunyan et al., 2013). However, this was conducted without consideration of possible pretest effects. We have shown that there was no pretest sensitization effect on knowledge and attitude, and this reveals that this effect could not modify the effect of the intervention among students and their mother. The implication of this finding is that a pretest can be done without concern about participants remembering the questions at a previous testing which may influence posttest scores.

This intervention suggests that education about the dangers of exposure to secondhand smoke and smoking to students in a short period may be useful in helping their family members to improve attitude, knowledge and selfconfidence in avoiding SHSe and persuading smokers to not smoke in their home.

The main limitation of this study is a failure to achieve random allocation of the intervention causing an imbalance of covariates, but were completely adjusted for on analysis. Another limitation, a 52\% increase in the odds of SFH but without statistical significance may suggest insufficient power of the study.

A school-based intervention can improve attitude and knowledge towards the harms of SHSe and smoking and self-confidence in creating a $\mathrm{SFH}$, avoidance of SHSe and persuading smokers not to smoke in the home but is ineffective in creating a SFH. Pretest sensitization in this context may not lead to changes in posttest scores.

\section{Acknowledgements}

We are grateful to the participants for their cooperation in the implementation and completion of this study. We acknowledge all school teachers, village health workers and volunteers, for their support in the conduct of the study.

\section{References}

Alwan N, Siddiqi K, Thomson H, et al (2011). Can a communitybased 'smoke-free homes' intervention persuade families to apply smoking restrictions at homes? J Public Health (Oxf), 33, 48-54.

Blanch C, Fernandez E, Martinez-Sanchez JM, et al (2013). Impact of a multi-level intervention to prevent secondhand smoke exposure in schoolchildren: a randomized cluster community trial. Prev Med, 57, 585-90.

Braver MC, \& Braver, S.L. (1988). Statistical treatment of the Solomon Four-Group Design:A meta-analytic approach. Psychological Bulletin, 104, 150-4.

Crone MR, Reijneveld SA, Willemsen MC, et al (2003). Prevention of smoking in adolescents with lower education: a school based intervention study. J Epidemiol Community Health, 57, 675-80.

Gao CM, Ding JH, Li SP, et al (2013). Active and passive smoking, and alcohol drinking and breast cancer risk in chinese women. Asian Pac J Cancer Prev, 14, 993-6.

Gehrman CA, Hovell MF (2003). Protecting children from environmental tobacco smoke (ETS) exposure: a critical review. Nicotine Tob Res, 5, 289-301.

Greenberg RA, Strecher VJ, Bauman KE, et al (1994). Evaluation of a home-based intervention program to reduce infant passive smoking and lower respiratory illness. J Behav Med, 17, 273-90.

Harutyunyan A, Movsisyan N, Petrosyan V, et al (2013). Reducing children's exposure to secondhand smoke at home: a randomized trial. Pediatrics, 132, 1071-80.

Herbert RJ, Gagnon AJ, O'Loughlin JL, et al (2011). Testing an empowerment intervention to help parents make homes smoke-free: a randomized controlled trial. J Community Health, 36, 650-7.

Huang HL, Yen YY, Lin PL, et al (2012). Household secondhand smoke exposure of elementary schoolchildren in Southern Taiwan and factors associated with their confidence in avoiding exposure: a cross-sectional study. BMC Public Health, 12, 40.

Israsena V (2007). Thai Teachers' Beliefs about Learner-centered Education: Implications for "Success for Life Thailand", University of North Texas.

Kegler MC, Bundy L, Haardorfer R, et al (2015). A minimal intervention to promote smoke-free homes among 2-1-1 callers: a randomized controlled trial. Am J Public Health, 105, 530-7.

Kegler MC, Escoffery C, Bundy L, et al (2012). Pilot study results from a brief intervention to create smoke-free homes. J Environ Public Health, 2012, 951426.

King BA, Mirza SA, Babb SD, et al (2013). A cross-country comparison of secondhand smoke exposure among adults: findings from the Global Adult Tobacco Survey (GATS). Tob Control, 22, 5 .

Kurtz ME, Kurtz JC, Contreras D, et al (2003). Knowledge and attitudes of economically disadvantaged women regarding exposure to environmental tobacco smoke: a Michigan, USA study. Eur J Public Health, 13, 171-6.

Lee J, Lee DR, Lee DH, et al (2015). Influence of maternal environmental tobacco smoke exposure assessed by hair nicotine levels on birth weight. Asian Pac J Cancer Prev, 16, 3029-34.

McCambridge J, Butor-Bhavsar K, Witton J, et al (2011). Can research assessments themselves cause bias in behaviour change trials? A systematic review of evidence from solomon 
4-group studies. PLoS One, 6, 25223.

Oberg M, Jaakkola MS, Woodward A, et al (2011). Worldwide burden of disease from exposure to second-hand smoke: a retrospective analysis of data from 192 countries. Lancet, 377, 139-46.

Pimhanam C, Sangrajrang S, Ekpanyaskul C (2014). Tobacco smoke exposure and breast cancer risk in Thai urban females. Asian Pac J Cancer Prev, 15, 7407-11.

Romanow L ( 2012). The women of Thailand. Global Majority E-Journal, 3, 44-60.

Solomon RL (1949). An extension of control group design. Psychol Bull, 46, 137-50.

Tahlil T, Woodman RJ, Coveney J, et al (2013). The impact of education programs on smoking prevention: a randomized controlled trial among 11 to 14 year olds in Aceh, Indonesia. BMC Public Health, 13, 367.

Task Force on Community Preventive S (2001). Recommendations regarding interventions to reduce tobacco use and exposure to environmental tobacco smoke. Am J Prev Med, 20, 10-5.

Tobacco Control Research and Knowledge Management Center (2012). Tobacco consumption control situation in Thailand, Bangkok, Jaruenmunkong Publisher.

World Health Organization (2009). WHO Report on the Global Tobacco Epidemic, 2009: Implementing smoke-free environments.

World Health Organization (2013). Guidelines on protection from exposure to tobacco smoke.

Yilmaz G, Caylan N, Karacan CD (2013). Brief intervention to preteens and adolescents to create smoke-free homes and cotinine results: a randomized trial. $J$ Trop Pediatr, 59, 365-71.

Zulkifli A, Abidin NZ, Abidin EZ, et al (2014). Implementation of smoke-free legislation in Malaysia: are adolescents protected from respiratory health effects? Asian Pac J Cancer Prev, 15, 4815-21. 